Вестник ВГУ. Серия: Право

УДК 341.231.14

DOI https://doi.org/10.17308/vsu.proc.law.2020.2/2818

\title{
СТАНДАРТЫ ЗАЩИТЫ ПРАВ ЧЕЛОВЕКА, ВЫРАБАТЫВАЕМЫЕ В ПРАКТИКЕ ЕВРОПЕЙСКОГО КОМИТЕТА ПО ПРЕДУПРЕЖДЕНИЮ ПЫТОК: ОСОБЕННОСТИ СТАТУСА И ПРАВОВОЕ ЗНАЧЕНИЕ
}

\author{
М. Ф. Косолапов
}

Саратовская государственная юридическая академия

Поступила в редакцию 22 марта 2020 г.

\begin{abstract}
Аннотация: расслатривается специфика деятельности Европейского комитета по предупреждению пыток, фбункиионирующего в ралках правозащитного механизла Совета Европы. Анализируются предпосылки, способствующие разработке ил международных стандартов, а также практических мер по защите лии, лишенных свободь, от пьток и иных фборл жестокого обращения. Ставится вопрос о статусе данных стандартов и их значении для национальных правовых систел.

Ключевые слова: защита прав человека, Совет Европь, лишение свободы, пылтки, жестокое обращение, Европейский колитет по предупреждению пыток, международный контроль, международные стандарты, наииональная правовая система.
\end{abstract}

Abstract: the article is devoted to the specifics of the activities of the European Committee for the Prevention of Torture acting within the framework of the human right mechanism of the Council of Europe. Conditions contributing to the development of international standards are analyzed, as well as the practical measures on the protection of persons, deprived of their liberty, from torture and other forms of cruel treatment. The issue of the status of these standards and its meaning for national legal systems is raised.

N Key words: human rights protection, the Council of Europe, deprivation of liberty, torture, cruel treatment, the European Committee for the Prevention of Torture, international supervision, international standards, national legal system.

В системе международных органов, фрункционирующих в сфрере защиты прав человека, Европейский комитет по предупреждению пыток и бесчеловечного или унижающего достоинство обращения или наказа-

294 ния (далее - ЕКПП или Комитет), созданный в рамках Совета Европы в 1987 г., занимает особое место ${ }^{1}$. Его структура, методы работы в значительной степени отличаются от тех, которые характерны для большинства контрольных органов, действующих в данной области.

Оказавшись встроенным в уже функционирующий правозащитный механизм Организации, ЕКПП был лишен полномочий по рассмотрению

${ }^{1}$ См.: Европейская конвенция по предупреждению пыток и бесчеловечного или унижающего достоинство обращения или наказания 1987 г. // Собр. законодательства Рос. Федерации. 1998. № 13. Ст. 1466. (Российская Федерация ратифицировала данную Конвенцию 28 марта 1998 г.)

(C) Косолапов М. Ф., 2020 
индивидуальных и межгосударственных жалоб, толкованию договорных норм: на момент его создания они уже находились в ведении Комиссии по правам человека и Европейского суда по правам человека (далее ЕСПЧ). В отличие от комитетов по правам человека ООН он не был наделен правом рассмотрения периодических докладов государств о реализации ими положений соответствующего договора ${ }^{2}$.

Своей главной цели - усиления защиты лиц, лишенных свободы, от пыток и бесчеловечного или унижающего достоинство обращения или наказания - он достигает благодаря организаџии посещений мест их содержания; внесения соответствующих предложений и рекомендаций участникам Конвенции, а также поддержания непрерывного диалога с государствами-членами в этой области (ст. 1 Конвенции 1987 г.). Еще одна особенность фонкционирования ЕКПП состоит в том, что Конвенция 1987 г. полностью посвящена вопросам его деятельности и, следовательно, в отличие от соответствующих комитетов ООН и ЕСПЧ он не осуществляет наблюдение за выполнением государствами-участниками положений Конвенции. Деятельность ЕКПП сосредоточена исключительно на общей превенции нарушений ст. 3 Конвенции о защите прав человека и основных свобод 1950 г., согласно которой «никто не должен подвергаться ни пыткам, ни бесчеловечному или унижающему достоинство обращению или наказанию», и на оказании помощи государствам в имплементации соответствующих стандартов на внутригосударственном уровне.

Отсутствие судебной (квазисудебной) функции в виде установления фрактов нарушения государствами взятых на себя обязательств осуществления абстрактного или казуального толкования договорных норм не позволяет говорить о возможности формирования в рамках деятельности ЕКПП правоприменительной практики по аналогии с перечисленными выше органами, а следовательно, и о возможности разработки им соответствующих международных стандартов.

В международной и внутригосударственной практике европейских государств, деятельности межправительственных и неправительственных международных организаций широкое распространение получило обращение к так называемым «стандартам Европейского комитета по предотвращению пыток». Особенно часто их можно встретить в практике ЕСПЧ ${ }^{3}$, Комитета Министров Совета Европы ${ }^{4}$. Как правило, данные органы ссылаются на стандарты ЕКПП в целях обоснования своей позиции

${ }^{2}$ Например, такое полномочие предоставлено Комитету по правам человека ООН согласно ст. 40 Международного пакта о гражданских и политических правах 1966 г.

${ }^{3}$ «Chernetskiy v. Russia» (жалоба № 18339/04) от 16 октября 2014 г. (§ 48) ; «Khoroshenko v. Russia» (жалоба № 41418/04) от 30 июня 2015 г. (§ 66) ; «Mehmet Eren v. Turkey» (жалоба № 32347/02) от 14 октября 2008 г. (§ 40) ; «Bouyid v. Belgium» (жалоба № 23380/09) от 28 сентября 2015 г. (§ 48) и т. д.

${ }^{4}$ Recommendation Rec(2006)2 of the Committee of Ministers to member states on the European Prison Rules. URL: https://wcd.coe.int (дата обращения: 06.04.2019). 


\section{Вестник ВГУ. Серия: Право}

по какому-либо вопросу или указывают на необходимость следовать им на внутригосударственном уровне в целях добросовестного выполнения взятых на себя обязательств. В распространении такой практики определенную роль сыграл и сам Комитет, подготовив и опубликовав сборник, озаглавленный «Стандарты ЕКПП», в котором были изложены «существенные» разделы из его общих отчетов ${ }^{5}$.

В отличие от кодифицированных стандартов, разрабатываемых международными организациями ${ }^{6}$, и стандартов, формируемых в рамках деятельности международных судебных (квазисудебных) органов, применение которых на внутригосударственном уровне перестало быть «правовой экзотикой», правовой статус стандартов ЕКПП до настоящего времени остается неопределенным и малоизученным.

В условиях отсутствия какого-либо конвенционного регулирования некоторое ориентирующее значение по отдельным вопросам формирования данных стандартов могут иметь позиции, изложенные Комитетом.

В своем Первом докладе, принятом в 1990 г. ${ }^{7}$, ЕКПП предпринимает попытку объяснить причину, побуждающую его к формированию данной группы стандартов, а также определить их место в системе международных стандартов прав человека (§ 95-96).

Комитет отмечает, что выполняемые им функции не предполагают какой-либо его организационной и правовой обособленности от других элементов действующей системы защиты прав человека. В своей деятельности он не ограничивается только положениями ст. 3 Конвенции 1950 г., источником правовой информации в рамках Совета Европы для него выступают правовые позиции ЕСПЧ и Комиссии по правам человека (до ноября 1998 г.), выработанные в ходе рассмотрения ими жалоб на предполагаемое нарушение данной статьи.

Помимо этого, учитывая, что «запрет пыток и бесчеловечного или унижающего достоинство обращения или наказания является общей международной нормой, которая в разных формулировках содержится в целом ряде международных документов»${ }^{8}$ ЕКПП ориентируется также

${ }^{5}$ CPT standards (CPT/Inf/E (2002) 1 - Rev. 2011. URL: http://www.psychargos. 296 gov.gr/Documents $2 / \% \mathrm{CE} \% 9 \mathrm{D} \% \mathrm{CE} \% 95 \% \mathrm{CE} \% 91 / \mathrm{eng}$-standards.pdf (дата обращения: 10.05.2019).

${ }^{6}$ См., например: Минимальные стандартные правила обращения с заключенными 1955 г. ; Свод принципов защиты всех лиц, подвергаемых задержанию или заключению в какой бы то ни было форме 1988 г. ; Минимальные стандартные правила Организации Объединенных Наций, касающиеся отправления правосудия в отношении несовершеннолетних (Пекинские правила) 1985 г.

${ }^{7} 1$ st General Report on the CPT's Activities (Nov. 1989 - Dec. 1990) (includes sections on Main features of the CPT, The emphasis placed on the preventive nature of the CPTs functions and Visits). URL: https://rm.coe.int/1680696a3е (дата обращения: 11.07.2019).

${ }^{8}$ European Convention for the Prevention of Torture and Inhuman or Degrading Treatment or Punishment Text of the Convention and Explanatory Report (CPT/Inf/C (2002) 1) (§ 26). URL: https://rm.coe.int/16806dbaa3 (дата обращения: 02.06.2019). 


\section{Международное и европейское право}

на стандарты, установленные в иных международных соглашениях, актах «мягкого права» и правоприменительных актах 9 .

Однако, несмотря на такое обилие нормативного и правоприменительного материала, имеющегося в распоряжении Комитета, во время проведения инспекций он сталкивается с конкретными ситуациями, для разрешения которых отсутствуют необходимые правовые ориентиры или требуется определенная «детализация» уже существующих международных стандартов ${ }^{10}$. В такой ситуации бездействие Комитета может повлечь негативные последствия и поэтому он вынужден «нащупывать свой путь к разработке собственных «подходов к оценке» («measuring rods») в свете опыта его членов и тщательного и хорошо сбалансированного сравнения различных систем содержания под стражей» ${ }^{11}$.

Согласно приведенной позиции «стандартизация» не является самоцелью, это скорее вынужденная мера. Комитет "включается» в процесс выработки «стандартов» только при отсутствии в системе действующего международного права формально-определенных критериев оценки условий содержания лиц, лишенных свободы, согласно требованиям ст. 3 Конвенции 1950 г.

Данное обстоятельство в какой-то мере предопределяет и место стандартов ЕКПП в системе международных стандартов прав человека. Комитет неоднократно отмечал, что он не претендует на самостоятельный статус своих «стандартов». В п. 21 Девятого ежегодного отчета, тематически касающегося правил содержания в местах лишения свободы несовершеннолетних лиц, Комитет подчеркнул, что любые стандарты, которые он может развивать в данной области, следует рассматривать как дополнение к содержащимся в комплексе международных документов, включая Конвенцию ООН 1989 г. о правах ребенка, Минимальных стандартных правилах $\mathrm{OOH,} \mathrm{касающихся} \mathrm{отправления} \mathrm{правосудия} \mathrm{в} \mathrm{отноше-}$ нии несовершеннолетних 1985 г., Руководящих принципах Организации Объединенных Наций для предупреждения преступности среди несовершеннолетних (Эр-Риядские руководящие принципы) ${ }^{12}$. В ряде случаев

\footnotetext{
${ }^{9}$ К такому роду документов можно отнести: Конвенцию против пыток и других жестоких, бесчеловечных или унижающих достоинство видов обращения и 297 наказания 1984 г. ; Минимальные стандартные правила обращения с заключенными 1955 г.; Свод принципов защиты всех лиц, подвергаемых задержанию или заключению в какой бы то ни было форме 1988 г. ; Минимальные стандартные правила Организации Объединенных Наций, касающиеся отправления правосудия в отношении несовершеннолетних (Пекинские правила) 1985 г. ; Европейские пенитенциарные правила 1987 г. и др.

${ }^{10}$ Cм. $§ 95.1$ st General Report on the CPT's activities covering the period November 1989 to December 1990. URL: https://rm.coe.int/1680696a3е (дата обращения: 11.07.2019).

${ }_{11}^{11}$ Мрган Р., Эванс М. Борьба против пыток в Европе М., 2002. С. 67. В монографиии данный термин интерпретируется как «нормативы».

${ }^{12}$ 9th General Report on the CPT's Activities (1998). URL: http://www.coe.int/en/ web/cpt/annual-reports (дата обращения: 11.07.2019). 


\section{Вестник ВГУ. Серия: Право}

Комитет напрямую указывает на оказываемое влияние действующих международных стандартов на его рекомендации государствам-участникам $^{13}$.

Представляется, что данную позицию Комитета необходимо воспринимать не как умаление статуса разрабатываемых им стандартов, а скорее как акцент на необходимость их учета в государственной практике наряду с положениями перечисленных актов, поскольку по ряду вопросов стандарты ЕКПП являются более детализированными и устанавливают более высокие требования к условиям содержания заключенных, чем аналогичные стандарты, содержащиеся в замечаниях общего порядка комитетов по правам человека $\mathrm{OOH}^{14}$ и в кодифицированных актах «мягкого права», принятых Генеральной Ассамблеей ООН. Неоспоримым преимуществом стандартов ЕКПП является также их постоянное развитие. Так, если в перечисленных универсальных стандартах вопросы содержания женщин, лишенных свободы, лиц иностранного гражданства, несовершеннолетних анализируются в общем контексте, то в актах ЕКПП проблемы, связанные с содержанием данных категорий лиц, рассмотрены достаточно подробно ${ }^{15}$. Кроме того, в своих докладах ЕКПП постоянно возвращается к наиболее проблемным вопросам, дополняя и развивая изложенные позиции ${ }^{16}$.

Представляется, что о потенциальной возможности формирования в рамках ЕКПП стандартов, не имеющих аналогов в международном праве, свидетельствует тот фракт, что Конвенция 1987 г. наделила его широкими полномочиями по сбору фрактической информации ${ }^{17}$ в рамках

${ }^{13}$ 25th General Report on the CPT's Activities (2015) (includes a section on the situation of life-sentenced prisoners). URL: http://www.coe.int/en/web/cpt/annualreports (дата обращения: 11.07.2019).

${ }_{14}$ General comment No. 20: Article 7 (Prohibition of torture, or other cruel, inhuman or degrading treatment or punishment) ; Замечание общего порядка № 2 Комитета против пыток ООН «Имплементация статьи 2 государствами-участниками». URL: http://tbinternet.ohchr.org (дата обращения: 12.05.2019).

15 10th General Report on the CPT's Activities (1999) (includes a section on Women deprived of their liberty) ; 13th General Report on the CPT's Activities (20022003) (includes a section on deportation of foreign nationals by air) ; 24th General

298 Report on the CPT's Activities (2013-2014) (includes sections on the phenomena of intimidation and reprisals and on juveniles deprived of their liberty under criminal legislation). URL: http:/www.coe.int/en/web/cpt/annual-reports (дата обращения: 12.05.2019).

${ }^{16}$ Например, проблема переполненности тюремных помещений неоднократно рассматривалась Комитетом : 2nd General Report on the CPT's Activities (1991), 7th General Report on the CPT's Activities (1996), 11th General Report on the CPT's Activities (2000).

17 Среди форм работы можно выделить: индивидуальные конфиденциальные беседы с лицами, лишенными свободы; право на свободное общение с любым лицом, которое с точки зрения Комитета может предоставить ему необходимую информацию (члены семей лиц, лишенных свободы; адвокаты; врачи; персонал, осуществляющий уход за данной категорией лиц); право запрашивать любую информацию по профилю Комитета у соответствующего государства. 


\section{Международное и европейское право}

посещения на территории государства мест лишения свободы (тюрьмы, полицейские участки, психиатрические лечебницы, военные учреждения, лагеря беженцев и т. д.), предоставив ЕКПП возможность аккумулировать и анализировать значительный объем фрактической информации об условиях содержания и практики обращения с лицами, лишенными свободы. Данное обстоятельство позволяет Комитету давать государствам-членам рекомендации, в которых поднимаются аспекты, не затрагиваемые ни в международных соглашениях, ни в рамках актов других международных органов ${ }^{18}$.

Особое значение рекомендациям, вырабатываемым в рамках деятельности ЕКПП, на наш взгляд, придает и профессиональный состав его членов. Конвенция 1987 г. четко не определяет профессиональные сферы, из которых могут быть назначены члены Комитета, указывая лишь, что «члены ЕКПП избираются из числа лиц, обладающих высокими моральными качествами, известных своей компетентностью в области прав человека или имеющие профессиональный опыт в областях, охватываемых настоящей Конвенцией». Как отмечал сам ЕКПП, предпочтительнее, чтобы в его состав включали лиц, имеющих опыт в вопросах управления тюрьмами, в различных сферах медицины, имеющих отношение к содержанию лиц, лишенных свободы, поскольку такой подход

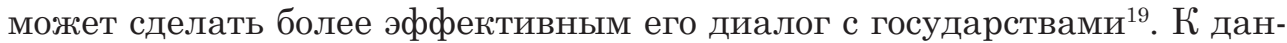
ной позиции Комитета можно добавить, что его «специфичный» состав более склонен к формулированию стандартов с учетом положений права, медицины, психологии и т. д. Например, разрабатывая стандарты, применимые к одиночному заключению, ЕКПП в первую очередь оценивает, как те или иные условия рассматриваемого ограничения сказываются на психическом, соматическом и социальном здоровье заключенного ${ }^{20}$.

В максимальной степени специфика разрабатываемых в ЕКПП стандартов выражена в Восьмом ежегодном отчете ${ }^{21}$, посвященном принудительному содержанию в психиатрических учреждениях, в связи с тем что положение данной категории лиц сопряжено с дополнительными ограничениями свободы, и без специальных познаний достаточно трудно дать оценку тем или иным фактическим обстоятельствам с точки зрения требований ст. 3 Конвенции 1950 г.

Значительное влияние на формирование стандартов ЕКПП, как следует из его ежегодных отчетов, оказывает анализ сложившейся вну-

${ }^{18}$ См.: Морган Р., Эванс М. Указ. соч. С. 210-211.

${ }^{19}$ См.: Европейская конвенция по предупреждению пыток и бесчеловечного или унижающего достоинство обращения или наказания. Текст Конвенции и Пояснительный доклад (CPT/inf/C 2002\1). URL: http://www.cpt.coe.int (дата обращения: 23.10.2019).

${ }^{20} 21$ st General Report on the CPT's Activities (2010-2011). URL: // http://www. coe.int/en/web/cpt/annual-reports (дата обращения: 11.07.2019).

${ }^{21} 8$ th General Report on the CPT's activities covering the period 1 January to 31 December 1997. URL: http://www.coe.int/en/web/cpt/annual-reports (дата обращения: 11.07.2019). 


\section{Вестник ВГУ. Серия: Право}

тригосударственной практики функционирования пенитенциарных учреждений. Сравнение условий содержания и методов работы с лицами, лишенными свободы, в различных государствах позволяет Комитету сделать вывод о том, что в большей степени соответствует требованиям ст. 3 Конвенции и какой положительный опыт может быть воспринят в качестве образца другими участниками Конвенции 1987 г. или, наоборот, чего следует избегать ${ }^{22}$.

Данные фракторы можно считать предпосылкой выделения рекомендаций ЕКПП из общей массы международных документов. Аналогичной точки зрения придерживается и Управление Верховного комиссара ООН по правам человека. В п. 39-42 «Стамбульского протокола» ${ }^{23}$ при оценке деятельности ЕККП отмечается: «Действуя подобным образом, Комитет постепенно выработал ряд ставших общими стандартами критериев обращения с лицами, содержащимися под стражей».

В качестве источника выработанных Комитетом «подходов к оценке» (measuring rods) могут выступать его ежегодные общие отчеты о деятельности, а также доклады по итогам посещения государства-участника. Однако их роль в этом качестве неравнозначна из-за имеющихся различий в целях принятия.

Первая группа актов носит исключительно персонифицированный характер: они направляются только правительству того государства, на территории которого осуществлялась проверка. В них Комитет излагает выявленные им в результате визита факты нарушения, прилагает свои выводы и включает при необходимости рекомендации и другие предложения по изменению ситуации, на основе которых строится диалог с государством ${ }^{24}$. Более того, содержащаяся в докладах информация конфиденциальна и может быть предана гласности только по просьбе (или с согласия) правительства. Лишь в случае отказа от сотрудничества o ЕКПП в виде «санкции» может принять решение и сделать публичное $Z$ заявление по сложившейся в стране ситуации (ч. 2 ст. 10 Конвенции) ${ }^{25}$.

${ }^{22}$ Например, практику создания специализированных центров для содержания несовершеннолетних преступников (CPT/Inf(2015)1-part) или подход к фpopмированию вспомогательного персонала в психиатрических учреждениях (СРТ/

$300 \operatorname{Inf}(98) 12$-part).

${ }^{23}$ Стамбульский протокол. Руководство по эффрективному расследованию и документированию пыток и других жестоких, бесчеловечных или унижающих достоинство видов обращения и наказания ООН. Нью-Йорк ; Женева, 2004. URL: http://www.ohchr.org/Documents/Publications/training8Rev1ru.pdf (дата обращения: 06.04.2019).

${ }^{24}$ См.: Доклад Правительству Российской Федерации, подготовленный Европейским комитетом по предотвращению пыток и бесчеловечного или унижающего достоинство обращения или наказания (ЕКПП) по итогам посещения Северо-Кавказского региона Российской Федерации с 27 апреля по 6 мая 2011 г. URL: https://rm.coe.int/1680697bd3 (дата обращения: 09.05.2019).

${ }^{25}$ Public statement concerning Belgium of 13 July 2017. (CPT/Inf (2017) 18) ; Public statement concerning the Chechen Republic of the Russian Federation of 10 July 2001 (CPT/Inf (2001) 15) ; Public statement concerning Greece of 15 March 2011 


\section{Международное и европейское право}

Таким образом, в силу имеющихся ограничений в отношении доступа к документу, а также казуального характера изложенной информации они вряд ли могут дать четкое представление о соответствующих стандартах.

В отличие от первой вторая группа актов (общие отчеты о деятельности) публикуется Комитетом самостоятельно и адресуется всем заинтересованным сторонам (государствам - участникам Конвенции 1987 г., международным органам и организациям, неправительственным правозащитным организациям). В них, как правило, ЕКПП излагает существенные вопросы, выяснению которых он уделяет внимание при осуществлении проверок мест лишения свободы. Посредством данных актов Комитет доводит до сведения органов Совета Европы, национальных властей и других заинтересованных субъектов свои позиции относительно правил обращения с лицами, лишенными свободы, а также стимулирует дальнейшее обсуждение этих вопросов как на международном, так и на внутригосударственном уровне. При этом общие доклады максимально нивелированы: в них отсутствуют какие-либо указания на страны, где были выявлены нарушения, органы государства и т. д.

Таким образом, в силу используемого подхода к изложению общедоступности именно положения ежегодных докладов Комитета можно воспринимать как источник выработанных им «measuring rods». В конечном итоге и сам Комитет позиционирует их «ключевые положения» как соответствующие стандарты ${ }^{26}$. Вместе с тем использование термина «стандарты» по отношению к позициям, излагаемым ЕКПП, достаточно условное и не должно восприниматься как некая аналогия стандартам, принятым в рамках $\mathrm{OOH} \mathrm{или} \mathrm{в} \mathrm{результате} \mathrm{деятельности} \mathrm{ЕСПЧ.} \mathrm{В} \mathrm{силу} \mathrm{своего} \mathrm{про-}$ исхождения они не могут быть отнесены к актам «мягкого права» (soft law) и не имеют прецедентного характера. Это предопределяет их особенности в системе международных стандартов прав человека.

Во-первых, с точки зрения изложения позиции Комитета в значительной степени отличаются от формулировок международных договоров или актов «мягкого права", так как Комитет не создает новых норм ${ }^{27}$, а скорее излагает критерии, на основе которых государство может разграничить то обращение, которое считается допустимым согласно ст. 3 Конвенции, а какое - нет. Так, в частности, рассматривая вопрос об использовании в психиатрическом учреждении средств усмирения, Комитет отмечает, что применение персоналом средств физического сдерживания пациентов (ремни, смирительные рубахи и т. д.) может осуществляться только

(CPT/Inf (2011) 10). URL: http://www.coe.int/en/web/cpt/public-statements (дата обращения: 14.07.2019).

${ }^{26}$ См.: Стандарты Европейского комитета по предупреждению пыток и бесчеловечного или унижающего достоинство обращения или наказания [CPT/Inf/E (2002) 1 - Rev. 2004]. URL: http://sutyajnik.ru/documents/3547.html (дата обращения: 09.05.2019).

${ }^{27} \S 96.1$ st General Report on the CPT's activities covering the period November 1989 to December 1990 (CPT/Inf (91) 3). URL: https://rm.coe.int/1680696a3e (дата обращения:16.06.2019). 


\section{Вестник ВГУ. Серия: Право}

в крайне редких случаях, носить кратковременный характер и всегда должно быть назначено врачом. Имеющаяся практика физического сдерживания на протяжении ряда дней или в качестве наказания не имеет терапевтического оправдания и, по мнению ЕКПП, равнозначна жестокому обращению ${ }^{28}$.

Во-вторых, стандарты, формулируемые ЕКПП, не всегда носят абсолютный характер, они достаточно «подвижны» и, по сути, представляют собой лишь примерные предписания. Такой подход в первую очередь обусловлен необходимостью учета большого числа факторов, как, например, в вопросе о том, что можно считать разумным размером камеры (или любого другого помещения) для содержания задержанного (заключенного) в полиции ${ }^{29}$. В нашем примере имеющееся незначительное отклонение от установленного ЕКПП минимального стандарта не всегда будет рассматриваться как составляющее бесчеловечное и унижающее достоинство обращение с заключенным, поскольку могут существовать другие, облегчающие ситуацию, факторы. При этом Комитет использует словосочетание «желаемый стандарт» ${ }^{30}$.

В-третьих, стандарты ЕКПП носят исключительно рекомендательный характер. Комитет при изложении своих позиций по ряду вопросов старается избежать какого-либо вторжения в чувствительные для государств сферы, используя следующие словосочетания: Комитет «полагает», «обеспокоен», «не одобряет», «желает подчеркнуть» и т. д. ${ }^{31}$ Однако данный факт не исключает, что они при определенных обстоятельствах могут обрести обязательное для государств значение посредством их одобрения прямо или косвенно ЕСПЧ или национальными судебными учреждениями.

На основании вышесказанного стандарты ЕКПП можно определить как изложенные в общих докладах позиции Комитета относительно требований, предъявляемых к условиям содержания лиц, лишенных свободы, с учетом положений ст. 3 Конвенции о защите прав человека и основных свобод 1950 г., сформулированные на основе анализа фрактических обстоятельств, установленных в результате проводимых проверок.

Что касается механизма действия стандартов ЕКПП на внутригосударственном уровне, а также степени их влияния на правовую систему

28 8th General Report on the CPT's Activities (1997) (includes a section on Involuntary placement in psychiatric establishments) CPT/Inf (98) 12. URL: https:// rm.coe.int/1680696a72 (дата обращения: 18.07.2019).

29 2nd General Report on the CPT's Activities (1991) (includes some substantives issues pursued by the CPT during visits: Police custody and Imprisonment). URL: http://www.coe.int/en/web/cpt/annual-reports (дата обращения: 09.05.2019).

${ }^{30}$ См.: Размер личного пространства на одного заключенного в пенитенциарных учреждениях : стандарты ЕКПП (CPT/Inf (2015) 44). URL: https://rm.coe. int/168073450f (дата обращения: 09.05.2019).

${ }^{31}$ См.: Стандарты тюремного заключения (выдержки из второго Общего доклада, опубликованного в 1992 г.) CPT/Inf (92) 3 (§ 47, 49, 50). URL: https://rm.coe. int/1680696a3f (дата обращения: 12.06.2019). 


\section{Международное и европейское право}

той или иной страны, то данные аспекты анализировать довольно трудно. Во-первых, существенным препятствием для такой оценки является закрепленная в Конвенции 1987 г. процедура конфиденциальности: без согласия проверяемой стороны как доклад, так и соответствующий отчет государства не может быть предан гласности, а на основе публикации отдельных документов полную картину выявленных нарушений и предпринимаемых в связи с этим действий со стороны государства представить достаточно сложно. Во-вторых, определенные трудности представляет и отсутствие на международном и внутригосударственном уровне какого-либо правового регулирования данных вопросов. Не выработаны соответствующие правовые позиции по рассматриваемому вопросу и в рамках судебной системы РФ. В-третьих, даже если государство воспринимает рекомендации ЕКПП, изложенные в докладах, или придерживается обобщенных стандартов, этот результат может быть замечен не сразу: для реализации некоторых рекомендаций требуются время и значительные финансовые ресурсы. Принятая в Российской Федерации Федеральная целевая программа, которая разрабатывалась в том числе

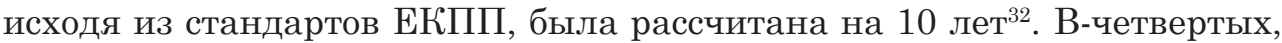
на наш взгляд, формальным препятствием является рекомендательный характер разрабатываемых Комитетом стандартов.

Тем не менее некоторые общие выводы о наличии определенного механизма учета рекомендаций можно сделать, исходя из соответствующих ответов правительства на замечания Комитета и положений внутригосударственного права, где присутствуют ссылки на стандарты ЕКПП принимаются меры для их реализации ${ }^{34}$.

Соответствующей реакцией государства на доклад Комитета может быть внесение поправок в действующие законы и подзаконные акты; корректировка действующей правоприменительной и иной практики, проведение расследований выявленных случаев нарушения и т. д..$^{35} \mathrm{~B}$ некоторых случаях предполагается учет выводов Комитета при рассмотрении отдельных категорий дел национальными судами ${ }^{36}$. Помимо этого,

$32 \mathrm{O}$ федеральной целевой программе «Развитие уголовно-исполнительной системы (2007-2016 годы)» : постановление Правительства РФ от 5 сентября 2006 г. № 540 // Собр. законодательства Рос. Федерации. 2006. № 39. Ст. 4075.

${ }^{33}$ См.: Доклад о результатах мониторинга правоприменения в Российской Федерации за 2015 год // Бюллетень Министерства юстиции РФ. 2017. № 1-3.

${ }^{34} \mathrm{O}$ мерах фризического стеснения при оказании психиатрической помощи : письмо Министерства здравоохранения РФ от 26 декабря 2002 г. № 2510/1296702-32 // Здравоохранение. 2003. № 3 .

${ }^{35}$ См.: Ответ Правительства РФ к докладу Европейского комитета по предотвращению пыток и бесчеловечного или унижающего достоинство обращения или наказания (ЕКПП) по итогам посещения Северо-Кавказского региона Российской Федерации с 27 апреля по 6 мая 2011 г. (CPT/Inf (2013) 2). URL: https://rm.coe. int/1680697bd5 (дата обращения: 12.05.2019).

36 Так, согласно постановлению Пленума Верховного Суда РФ от 14 июня 2012 г. № 11 «О практике рассмотрения судами вопросов, связанных с выдачей лиц для уголовного преследования или исполнения приговора, а также переда- 


\section{Вестник ВГУ. Серия: Право}

несмотря на то что стандарты ЕКПП главным образом адресованы государственным структурам, их положения могут быть использованы гражданами и правозащитными организациями при защите прав и свобод.

чей лиц для отбывания наказания», суды общей юрисдикции при принятии решения могут учитывать, помимо других документов, доклады ЕКПП (см.: Бюллетень Верховного Суда Российской Федерации. 2012. № 8).

Саратовская государственная юридическая академия

Косолапов М. Ф., кандидат юридических наук, доцент кафбедры международного права

E-mail: kosolapov_mf@mail.ru
Saratov State Law Academy

Kosolapov M. F., Candidate of Legal Sciences, Associate Professor of the International Law Department

E-mail: kosolapov_mf@mail.ru 